\title{
Translational toxicology and exposomics for food safety risk management
}

\author{
Yongning Wu
}

From 2012 Sino-American Symposium on Clinical and Translational Medicine (SAS-CTM)

Shanghai, China. 27-29 June 2012

\section{Background}

China embraces the use of risk analysis in the development of risk-based approaches for the management of public health hazards in food safety. Risk analysis is made up of three components and Figure 1 illustrates the relationship between the three components of risk analysis [1]. Estimating the magnitude and distribution of benefits and costs of particular risk management options may require addressing a myriad of concerns, e.g., changes in the availability or nutritional quality of foods; impacts on consumer confidence in the safety of the food supply or in the food regulatory system [2]. This is a brief introduction on risk management options for dealing with the new outcome from risk assessment approaches in China.

\section{Materials and methods}

Traditionally, risk assessment is based on deterministic endpoints, i.e., use of the no observed (adverse) effect level (NO(A)EL) and the mean or high level of exposure.

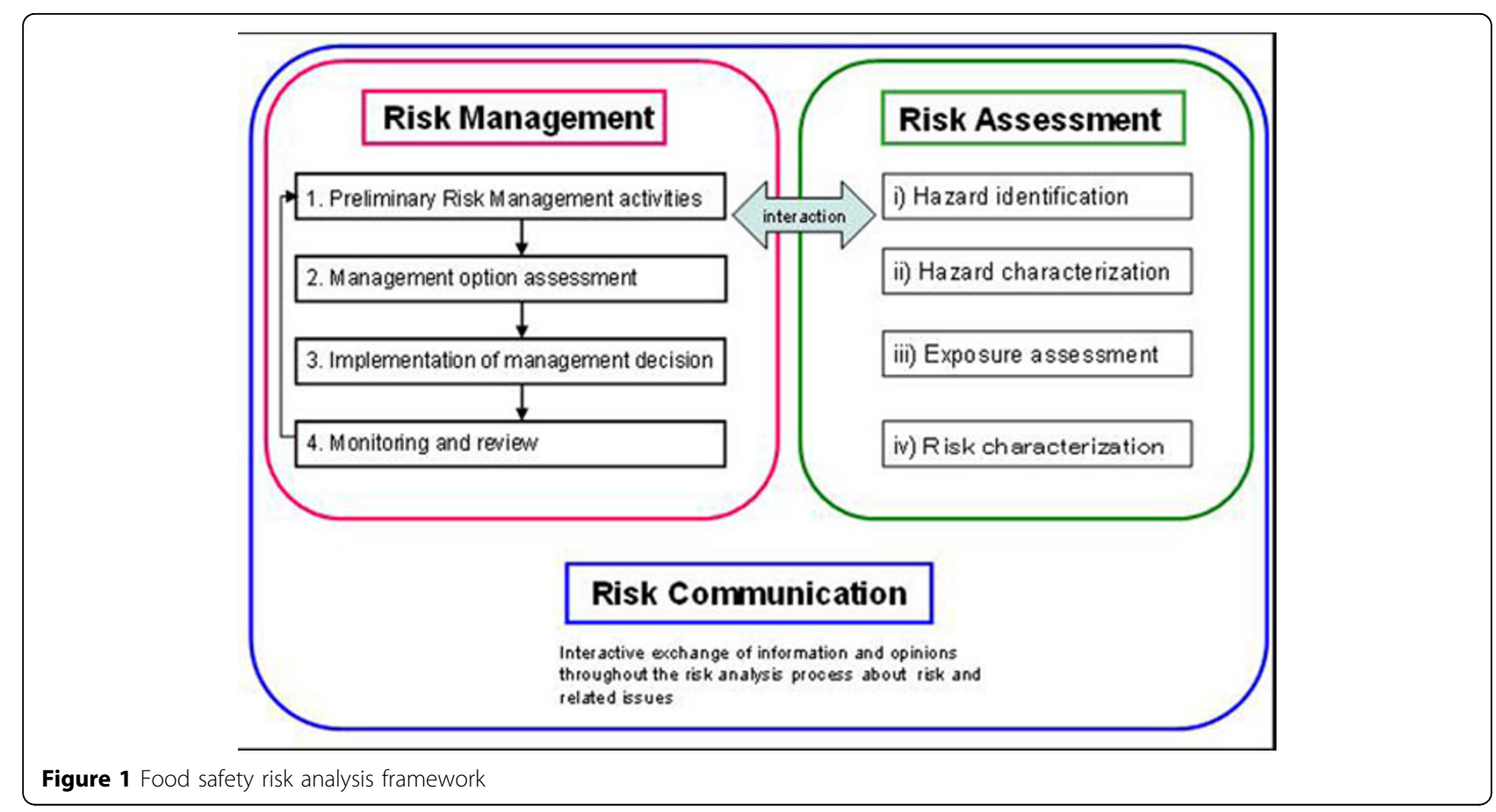

Correspondence: wuyncdc@yahoo.com.cn

China National Center for Food Safety Risk Assessment, Beijing, 100050,

China

C Biomed Central
(C) 2012 Wu; licensee BioMed Central Ltd. This is an Open Access article distributed under the terms of the Creative Commons Attribution License (http://creativecommons.org/licenses/by/2.0), which permits unrestricted use, distribution, and reproduction in any medium, provided the original work is properly cited. 
In the 21 st century, exposure science has increasingly embraced deterministic models to predict levels of diverse exposures based on categorical data and on measured levels of pollutants in biological fluids and tissues. Increasingly, more probabilistic and distributional methods are included, to characterize the hazard(s) as well as the exposure(s). Investigations of total personal exposure initially employed external measurements of chemicals that can enter the body, which provide the more probabilistic and distributional methods. These approaches allow for more description of variability in the population as well as uncertainty in the risk estimates. Moreover, additional risk assessment outcomes are being reported, such as the margin of exposure (MOE), which gives a relative indication of the level of health concern with actually quantifying the risk [3-5].

\section{Results}

The manner in which health reference guide values (HBGVs) such as the acceptable, tolerance, and reference

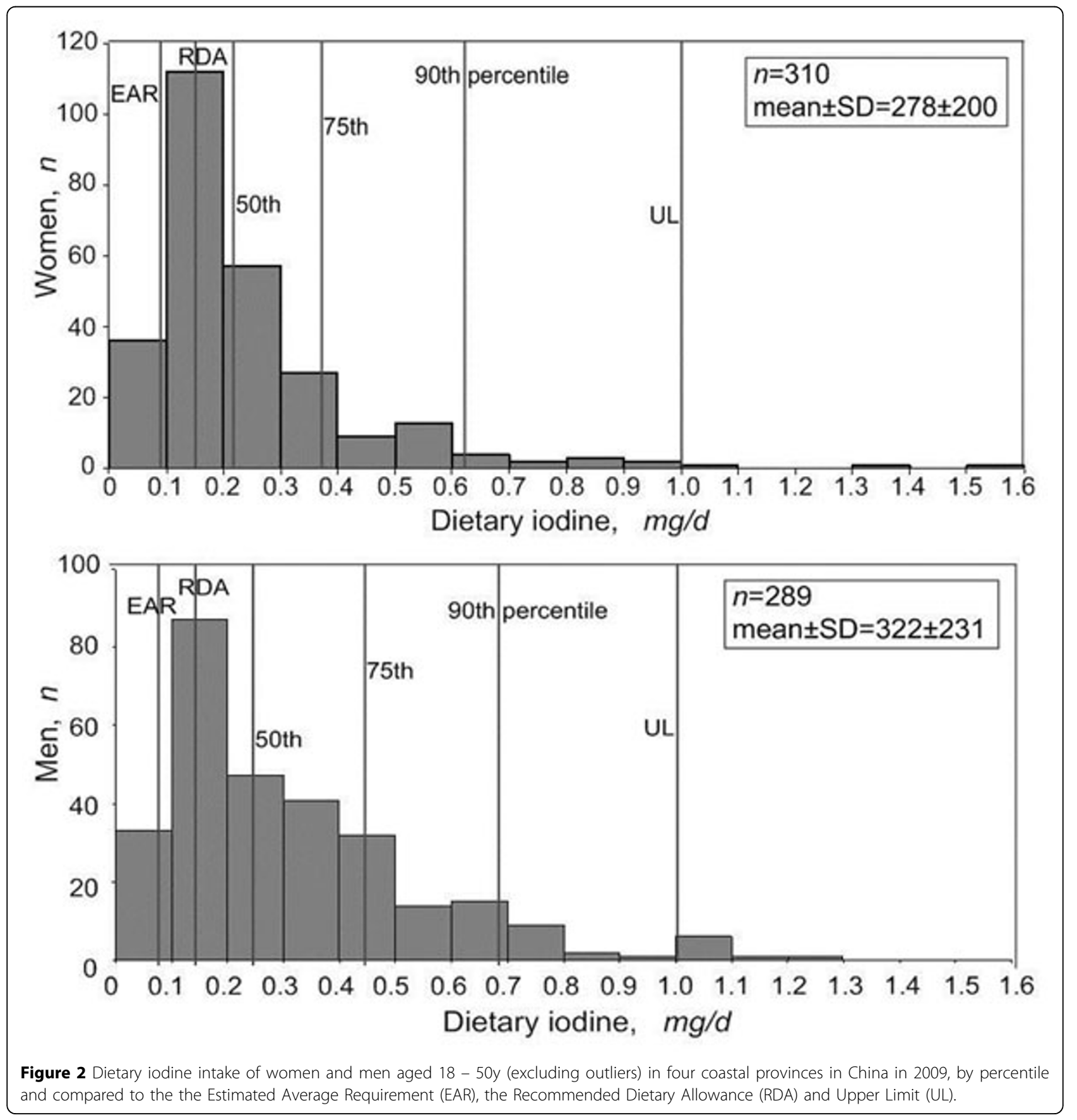


Table 1 Diet Exposure for Inorganic Arsenic (iAS) in Rice for various Cluster Diet (g/Kg.bw per day)*

\begin{tabular}{lccccccccccccc}
\hline Cluster Diet & A & B & C & D & E & F & G & H & I & J & K & L & M \\
\hline Rice Consumption (g) & 91.0 & 31.6 & 94.6 & 33.2 & 12.7 & 12.7 & 376.9 & 64.3 & 38.0 & 74.3 & 238.4 & 381.3 & 34.6 \\
\hline Average iAs Intake & 0.17 & 0.06 & 0.17 & 0.06 & 0.02 & 0.02 & 0.69 & 0.12 & 0.07 & 0.14 & 0.44 & 0.70 & 0.06 \\
\hline P90 iAs Intake & 0.30 & 0.11 & 0.32 & 0.11 & 0.04 & 0.04 & 1.26 & 0.21 & 0.13 & 0.25 & 0.79 & 1.27 & 0.12 \\
\hline P99 iAs Intake & 0.46 & 0.16 & 0.47 & 0.17 & 0.06 & 0.06 & 1.88 & 0.32 & 0.19 & 0.37 & 1.19 & 1.91 & 0.17 \\
\hline
\end{tabular}

dose (RfD) are estimated usually generates deterministic values in that they imply a demarcation between what is a "safe" level of exposure (i.e., exposures below the value) versus a "non-safe" level (i.e., exposures above the value). In many instances over the years, these deterministic values have been used as a common "bright line" approach to managing risk. Decision makers and competent authorities use these reference values to set standards and regulations for what are appropriate exposures. If uncertainty and variability be kept in mind, probabilistic modeling (e.g., with distributions around the values) provides risk managers more detailed dose response modeling with greater transparency of the uncertainty surrounding many of these values. To aid the decision, the risk assessment should provide information on the nature and magnitude of uncertainties in both the toxicological and exposure data that make up the inputs to the distributions being modeled.

For risk managers, the distribution around the reference value and its probabilities and uncertainties makes decision making more complicated, particularly about who specifically or what portion of a population to protect. Considerations need to be made regarding whether the most sensitive individual(s) needs to be protected or the bulk of the general population (e.g., to decide on a

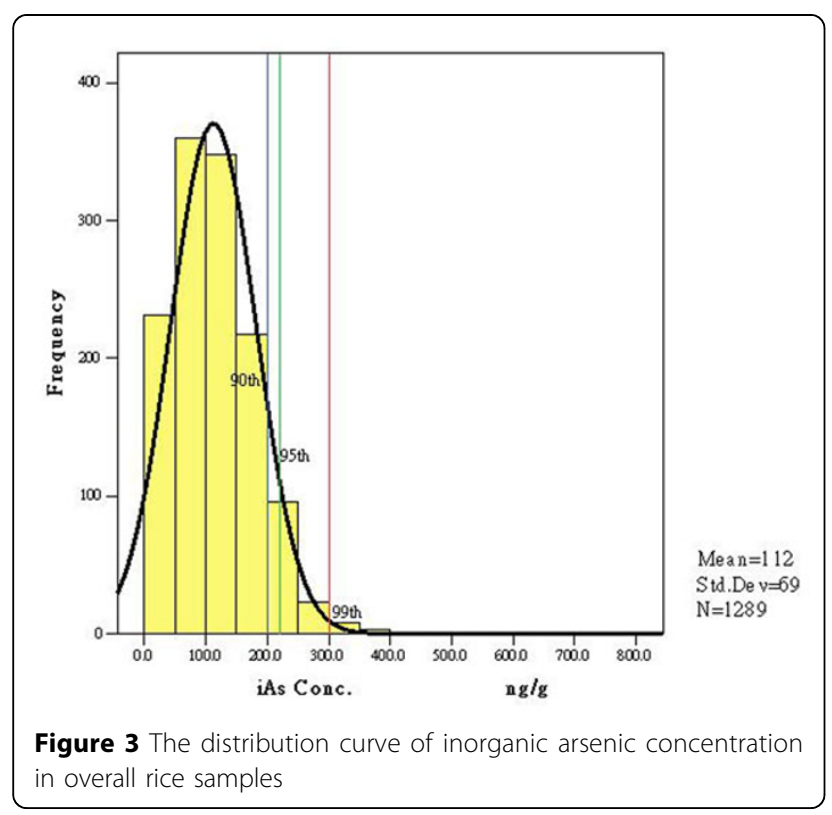

goal that at least $95 \%$ of any population should not exceed the acceptable/tolerance intake (in some cases this could be a long term goal)). For some contaminants, it may be useful to establish more than one reference value (e.g., a RfD for the general population and an acute RfD for pregnant women). The two examples will be summarized for risk-benefit analysis for universal iodized salt (figures 2) [6] and maximum limit development of inorganic arsenic in rice (table 1 and figures 3 ).

\section{Conclusions}

One can imagine a future in which individuals' exposomes are contrasted between diseased and healthy populations for molecular epidemiology. In either case, the goal would be to discover causes of ill health and to generate hypotheses regarding identification and elimination or reduction of harmful exposures. These expansions of risk assessment tools and information provided require additional risk management approaches, included in the platform to translational toxicology and exposomics.

\section{Acknowledgements}

The paper was funded by the National Basic Research Program of China (973 Program 2012CB720804), National Key Technology R\&D Program (2006BAK02A01 \& 2012BAK01B01), and China Ministry of Health (grant number 200902009).

\section{Published: 17 October 2012}

\section{References}

1. Abt E, Rodricks J, Levy J, Zeise L, Burke T: Science and decisions: Advancing risk assessment. Risk Analysis 2010, 30:1028-1036.

2. Carrington C, PM Bolger: The limits of regulatory toxicology. Tox Appl Pharmacol 2010, 243:191-197.

3. Slob W, MN Pieters: A probabilistic approach for deriving acceptable human intake limits and human health risks from toxicological studies: general framework. Risk Analysis 1998, 18:787-798.

4. Lioy P, Rappaport SM: Exposure Science and the Exposome: An Opportunity for Coherence in the Environmental Health Sciences. Environ Health Prespect 2012, 119:A466-469.

5. Wild CP: Complementing the genome with an "exposome": the outstanding challenge of environmental exposure measurement in molecular epidemiology. Cancer Epidemiol Biomarkers Prev 2005, 14(8):1847-1850.

6. Wu YN, Li XW, Chang SY, Liu LP, Zou SR, Hipgrave D: Variable iodine intake persists in the context of universal salt iodization in China. J Nutr 2012.

doi:10.1186/1479-5876-10-S2-A41

Cite this article as: Wu: Translational toxicology and exposomics for food safety risk management. Journal of Translational Medicine 2012 10(Suppl 2):A41. 